Sociohistórica

ISSN: 1852-1606

publicaciones@fahce.unlp.edu.ar

Universidad Nacional de La Plata

Argentina

\title{
Las organizaciones de trabajadores desocupados en Bahía Blanca: un análisis sociohistóricode sus principales características (1995- 2003)
}

Becher, Pablo Ariel

Las organizaciones de trabajadores desocupados en Bahía Blanca: un análisis sociohistóricode sus principales características (1995- 2003)

Sociohistórica, núm. 46, 2020

Universidad Nacional de La Plata, Argentina

DOl: https://doi.org/10.24215/18521606e112

Atribución no comercial compartir igual (CC BY-NC-SA) 4.0 
Artículos

\section{Las organizaciones de trabajadores desocupados en Bahía Blanca: un análisis sociohistóricode sus principales características (1995- 2003)}

The organizations of unemployed workers in Bahía Blanca: a sociohistorical analysis of its main characteristics
$(1995-2003)$

Pablo Ariel Becher

DOI: https://doi.org/10.24215/18521606e112

Universidad Nacional del Sur, Argentina

pablobecher@hotmail.com

Recepción: 24 Mayo 2019

Aprobación: 19 Diciembre 2019

Recepción: 24 Mayo 2019

Aprobación: 19 Diciembre 2019

\section{Resumen:}

En la ciudad de Bahía Blanca (Argentina), el surgimiento del movimiento de trabajadores desocupados (MTD) tuvo lugar en 1995, como efecto de las privatizaciones y la recesión económica. La conflictividad de las organizaciones de desocupados inició profundos procesos de transformación social, que modificaron las políticas públicas del Estado y reconfiguraron el entramado político a nivel local y regional. Hacia el año 2003, se observó un declive del movimiento de desocupados en la ciudad, producto de un cambio político y una nueva coyuntura económica a nivel nacional. A través del estudio de las principales características de las organizaciones involucradas, este trabajo analiza las estrategias políticas llevadas a cabo por esos sectores para comprender los mecanismos de organización y su relación con el entramado de disputas entre fuerzas sociales. Se utilizó una metodología basada en la realización de entrevistas en profundidad y el análisis de documentos periodísticos y de archivos no editados.

Palabras Clave: Conflictividad laboral, Estrategias políticas, Fuerzas sociales, Organizaciones de trabajadores desocupados.

\section{ABSTRACT:}

In the city of Bahía Blanca (Argentina), the emergence of the unemployed workers movement (BAT) took place in 1995, as a result of privatizations and the economic recession. The unrest of the unemployed organizations initiated deep processes of social transformation, which modified public policies of the State and reconfigured the political fabric at the local and regional level. Towards the year 2003, there was a decline in the movement of unemployed people in the city, as a result of a political change and a new economic situation at a national level. Through the study of the main characteristics of the organizations involved, this paper analyzes the political strategies carried out by these sectors to understand the mechanisms of organization and their relationship with the framework of disputes between social forces. A methodology based on conducting in-depth interviews and analyzing journalistic documents and non-edited archives was used.

KeYwORDS: Labour Conflict, Political strategies, Social forces, Organizations of unemployed workers.

\section{INTRODUCCIÓN}

Durante la década de 1990 se llevó a cabo una reestructuración de la economía argentina, que profundizó las políticas neoliberales instauradas por la última dictadura cívico militar de 1976-1983. Este proceso significó una fuerte desregulación de los mercados, apertura comercial y financiera, y privatización de los servicios públicos, lo que consolidó el proceso de concentración y centralización económica (Schorr, 2005), y un retroceso en las conquistas económicas y sociales de los trabajadores (Izaguirre, 2003). En este contexto nacional, las transformaciones generaron elevadas tasas de desocupación, subempleo, precarización e informalidad, que impactaron directamente en el incremento del empobrecimiento y en la vulnerabilidad de amplios sectores sociales (Torrado, 2010). Esta situación tuvo su contracara en el surgimiento de distintas experiencias y organizaciones de resistencia que enfrentaron el proceso de desigualdad social y concibieron 
distintas alternativas políticas. Estos movimientos sociales presentaron un conjunto de demandas y acciones con una fuerte carga de conflictividad (Bonnet y Piva, 2009). Entre las más importantes, por su capacidad de organización y por la escalada de conflictos y debates que generó, se encuentra el movimiento de trabajadores desocupados (MTD) (Svampa y Pereyra, 2003).

El MTD ha sido motivo de numerosas investigaciones a nivel nacional, en ellas confluyen diferentes perspectivas de trabajo que analizan el conflicto social y la estructura económica, sus acciones colectivas y la formación de identidades colectivas (Manzano, 2004; D'Amico y Pinedo, 2009). Todas las organizaciones de desocupados tuvieron desde sus orígenes una manifiesta heterogeneidad, atravesadas por diferentes tradiciones organizativas y corrientes político-ideológicas (Svampa y Pereyra, 2003; Artese, 2009). En los últimos años, las perspectivas de estudio antropológicas han destacado una serie de puntos importantes en torno a la vida cotidiana y a las formas de organización de los sectores populares, y han visibilizado la complejidad en las relaciones internas de los MTD. Sin embargo, la apelación a las relaciones de clase y la construcción de la conflictividad han sido devaluadas como ejes de análisis frente a una visión crítica de la lucha de clases (Becher, 2018). El presente estudio rescata el interés de la perspectiva marxista en la constitución de los movimientos sociales como expresiones colectivas de las disputas entre diversas fuerzas sociales a nivel local (Gómez, 2012; Galafassi, 2017). ${ }^{1}$

El objetivo planteado implica describir y analizar las organizaciones políticas y sociales que integraron el movimiento de trabajadores desocupados durante el período 1995-2003 en la ciudad de Bahía Blanca. ${ }^{2}$ Se ha priorizado la metodología cualitativa del análisis social, a partir del registro de entrevistas en profundidad hechas a los actores intervinientes dentro de los MTD (ya sea referentes, líderes o militantes de base) y al uso de fuentes periodísticas y archivos no editados (volantes, propagandas, escritos personales, etc.). Entre los periódicos utilizados a nivel local se hará hincapié fundamentalmente en La Nueva Provincia y EcoDias. ${ }^{3}$

En la ciudad de Bahía Blanca, ubicada al sudoeste de la provincia de Buenos Aires (Argentina), la aparición de las primeras organizaciones de trabajadores desocupados tuvo lugar en 1995, un año particularmente conflictivo a nivel nacional (Piva, 2012). Las luchas de los desocupados iniciaron profundos procesos de transformación social, que modificaron las políticas públicas y definieron un nuevo marco de acción de las propias organizaciones sociales y/o partidos políticos hasta la actualidad. Hacia el año 2003, y luego de diferentes procesos históricos, se generó un declive en la dinámica del movimiento de desocupados de la ciudad, en el marco de un cambio hegemónico en la correlación de fuerzas sociales, y de una nueva etapa política marcada por la asunción de nuevas autoridades a nivel nacional, provincial (Buenos Aires) y local, quienes tejerán otro tipo de relaciones con el movimiento obrero en general (Svampa, 2008).

El trabajo se estructura en tres partes: en una primera aproximación se describe brevemente el contexto socioeconómico de la ciudad de Bahía Blanca y los procesos de conflictividad laboral que formaron parte del momento histórico en el cual surgieron las primeras organizaciones de desocupados. Luego se proponen una serie de apartados sobre cada organización de trabajadores desocupados desde 1995 hasta el 2003. En esta segunda parte se rastrea cómo se van configurando esas fuerzas sociales, principalmente la fracción de los desocupados; para ello se recurre a la retrospectiva histórica, al análisis de diversos documentos y de entrevistas semiestructuradas. ${ }^{4}$ Por último, se analizan las características generales del movimiento para cerrar con un conjunto de conclusiones provisorias.

\section{CONTEXTO SOCIOECONÓMICO LOCAL Y CONFLICTIVIDAD LABORAL A MEDIADOS DE 1990}

Bahía Blanca se ha caracterizado históricamente como una ciudad de servicios y actividades comerciales, con una gran industria relacionada con la petroquímica y un peso importante en la exportación de productos agropecuarios. En la década de 1990 su nivel de desocupación, informalidad y precarización laboral superaba 
ampliamente diversas ciudades del país, con cifras cercanas a un $20 \%$ de personas sin empleo y un $12 \%$ en subempleo (Gorenstein, Cerioni, Scudelati, 1995).

Políticamente, la ciudad portuaria estaba atravesada por la dinámica nacional y provincial, y tuvo como partido gobernante durante un largo período (1991-2003) a la Unión Cívica Radical, bajo la intendencia de Jaime Linares. Este gobierno asumió una vinculación ambivalente con el peronismo en el poder (tanto a nivel nacional como provincial), tanto en los períodos de Eduardo Duhalde (1991- 1999) como de Carlos Ruckauf (1999-2002). Esta compleja situación pudo sortearse a través de alianzas y negociaciones permanentes por el presupuesto, lo cual imprimió a la gestión "linarista" un marcado pragmatismo político. Durante su primer período en la década de 1990, a las dificultades financieras que representó para las intendencias el pacto fiscal de 1992, se le sumaron recortes presupuestarios, ajustes fiscales, y un alarmante aumento del desempleo, que convirtió a la ciudad en un punto nodal de la pobreza, en medio de una reconfiguración económica de Bahía Blanca, que pasaba a ser un polo para la industria petroquímica y la actividad de los hipermercados (Heredia Chaz, 2018).

Las problemáticas de los sectores populares en la ciudad se remontan a fines de la década de 1980, cuando el modelo de crecimiento basado en el sector agroexportador comenzó a tener sus límites, en medio de un proceso inflacionario que afectó el salario real de los trabajadores. A partir de 1990, la privatización de empresas públicas, con el auspicio de sectores sindicales y políticos, generó una expulsión de trabajadores estatales y privados en diferentes ámbitos, lo que propició el trabajo cuentapropista principalmente en el comercio minorista, servicios de transportes, venta ambulante o el trabajo domiciliario textil o metalúrgico. Estas actividades no fueron acompañadas por políticas estatales que protegieran el mercado emergente y terminaron en muchos casos como trabajos de autoexplotación, que se desintegraron en un breve lapso entre 1992 y 1994.

Un estudio realizado por Caritas Arquidiocesana demostraba que el desempleo en 1995 afectaba a 3.564 familias, sobre un relevamiento realizado en 23 centros que funcionaban en la ciudad (La Nueva Provincia, 29 de agosto de 1995 , p. 4). De ese porcentaje de familias, que sumaba alrededor de 16.500 personas, un 34 $\%$ tenía ocupación sobre un total de 65,8 \% de inactivos (INDEC-EPH, 1995). A partir de la divulgación de estos datos, el municipio bahiense decretó a fines de 1995 la emergencia agropecuaria; confirmó la reducción presupuestaria para 1996, junto con una reformulación del plan de obras públicas y un plan de privatizaciones (La Nueva Provincia, 30 de agosto de 1995, p. 9).

El desempleo mostró durante todo el período una dinámica compleja: se duplicó -pasó del $10 \%$ al $20 \%$ entre 1991 y 1995, y continuó en niveles muy altos hasta 2003, con la excepción de una breve baja entre 1998 y 2000, según datos de la Encuesta Permanente de Hogares y el Centro Regional de Estudios Económicos Bahía Blanca - Argentina (CREEBBA). Esta situación se dio en el marco de una flexibilización laboral, junto con la incorporación femenina al trabajo, y el ingreso al PEA de jóvenes desempleados y jubilados. Esta creación de empleos y (la reconversión de los existentes) implicó una precarización generalizada de puestos, con la consiguiente inestabilidad de ingresos salariales. Asimismo, se verificó un aumento significativo del empleo no registrado -pasó del $24 \%$ en 1995 a casi un 40 \% en 2003-, lo que explicaría el aumento en la población sobrante, ${ }^{5}$ medida no solo a partir de los desempleados del sector formal sino también por la subocupación demandante y no demandante (Becher, 2018).

A mediados de la década de 1990, mientras en el contexto nacional se generaban levantamientos de trabajadores desocupados y conflictos piqueteros, principalmente en Río Negro y Neuquén, ${ }^{6}$ en la provincia de Buenos Aires, las primeras manifestaciones de desocupados tuvieron lugar en Bahía Blanca, entre septiembre y octubre de 1995, a partir de un petitorio de firmas, con ocupación de la plaza central y una manifestación que se hizo extensiva a los núcleos barriales (Oviedo, 2004).

El proceso de organización de MTD en Bahía Blanca empezó a formarse a partir de la conjugación de varios factores, relacionados con el proceso a nivel nacional: por un lado, el desconcierto que generaba el "peronismo menemista", que paso del "salariazo" al ajuste fiscal; la descomposición y fragmentación del sindicalismo 
como actor principal en la disputa contra el capital y los intereses de las clases dominantes en el gobierno; la aceleración del proceso de pauperización, combinado con la falta de empleo, los problemas de infraestructura en los barrios, las pérdidas que acarrearon las indemnizaciones, un sentimiento de elevada impotencia frente al avasallamiento de cualquier tipo de derecho social.

Además de estos factores, la conflictividad laboral en la ciudad desde mediados de la década de 1990 se destacó por un creciente malestar en relación a las jubilaciones y retiros anticipados (sector bancario), las nuevas concesiones privadas (sector de energía -como ESEBA-, trabajadores del correo argentino, aeronáuticos y colectiveros), pero también por los acuerdos y las negociaciones de los sindicatos con las empresas, lo que se tradujo en un recrudecimiento del conflicto intersindical, ${ }^{7}$ con comisiones directivas y cuerpos de delegados que demandaban una democratización sindical. Los despidos compulsivos cobraron una dinámica importante en el sector manufacturero local, tanto en la rama textil, el sector de la carne, de pescadores y pelado de camarones en la zona de Ing. White.

En los años posteriores al período 1997-1999 comenzó la formación de un núcleo de fuerzas sociales que resistían al avance neoliberal. En muchos casos, esa resistencia cobró diferentes magnitudes y agrupó a diversos sectores sociales como los docentes, estatales, estudiantes, jubilados, médicos, trabajadores de la salud, y trabajadores de la cultura, que fortalecieron los lazos de unidad y los reclamos unificados en grandes movilizaciones, ocupaciones callejeras y de edificios públicos.

Estos hechos locales dan cuenta de la conflictividad y el desarrollo de la desocupación en la ciudad, que llevará a la conformación de las primeras organizaciones independientes de desocupados, como la Unión de Trabajadores Desocupados, con un apoyo inicial de la CTA local, Caritas y otros sectores sociales. Hacia fines de 1999 y 2002, los procesos de conflictividad social prefiguran una nueva etapa de ascenso en las luchas de la población sobrante junto con un movimiento obrero fragmentado y diezmado. Este período relacionado con el gobierno de la Alianza (Frente País Solidario - UCR) expresará la conformación de un nuevo núcleo de organizaciones de trabajadores desocupados, con experiencias diversas, esta vez bajo la dirección política de organizaciones a nivel nacional como la Corriente Clasista Combativa (CCC), Polo Obrero (PO) y Movimiento Territorial de Liberación (MTL), algunas de ellas ligadas a partidos políticos de izquierda. A continuación se brindará una serie de detalles de las organizaciones que constituyeron este movimiento en la ciudad de Bahía Blanca para dar cuenta de sus formas de organización y experiencias de lucha.

\section{La UTD como PRimera organización de desocupados en BaHÍa Blanca (1995)}

Como expresamos anteriormente, 1995 se convirtió en un año bisagra para el nacimiento del MTD en Bahía Blanca, debido a la intensidad de la desocupación. En septiembre de 1995, una agrupación independiente de partidos políticos, llamada Unión de Trabajadores Desocupados (UTD), comenzó a sumar firmas con el objetivo de elevar un petitorio a la Municipalidad, solicitando un subsidio de 500 pesos (destinado a todos los desempleados sin discriminación), y la cesión de tierras del ferrocarril para la realización del programa ProHuertas del Instituto Nacional de Tecnología Agropecuaria (INTA) (La Nueva Provincia, 24 de septiembre de 1995).

Como expresaba un dirigente de la organización: "La UTD estaba conformada por un extrabajadores ferroviarios y de la construcción, empleados por el Estado antes de su desmantelamiento, que sufrieron un fuerte deterioro en sus condiciones de vida" (Gerardo, comunicación personal, 11 de febrero de 2015). Algunos de los referentes de la UTD tuvieron un pasado militante en el Movimiento al Socialismo y en la formación de Izquierda Unida, ${ }^{8}$ hasta que decidieron su salida de la agrupación por diversos motivos.

En un documento realizado en febrero de 1995, "La carta programática de la UTD", se expresaban claramente una fundamentación y un método para organizar a los desocupados. Se incluían en el petitorio demandas puntuales. ${ }^{9}$ Se planteaba un reclamo legalista para exigir el compromiso y la responsabilidad de los 
actores políticos en brindar una solución a la desocupación. Se intentó establecer un diálogo que pusiera en debate cinco puntos cruciales para la vida diaria del desocupado: su reconocimiento como organización, ${ }^{10}$ la posibilidad de acceder a tierras para realizar trabajos autogestionables, el acceso a la vivienda, exención del pago de servicios y posibilidad de viajar gratuitamente por el territorio nacional en la búsqueda de un trabajo.

Para sostener el movimiento, se decidieron a ocupar la plaza con un acampe prolongado de dos meses y cinco días (septiembre y octubre de 1995), utilizando una carpa colectiva. Su preocupación era la de reevaluar el empadronamiento municipal de los desocupados bahienses (unas 2.500 personas) para ampliarlo y facilitar una ayuda alimentaria en distintos barrios. La Secretaría de Acción Social del Municipio prefería ingresar los datos de los desocupados y seleccionar quienes recibirían los planes, situación indeseada por la UTD, que veía en ello los peligros del clientelismo (La Nueva Provincia, 3 de octubre de 1995, p. 4).

En otra entrevista a una mujer referente de la UTD nos comentaba sobre el acompañamiento de las organizaciones de izquierda y de medios alternativos (entre ellos, la radio FM De la Calle) como una constante en todas las acciones colectivas y en la metodología de organización (Ana, comunicación personal ,18 de febrero de 2015). Por el contrario, "el sindicalismo cegetista no aportó ningún tipo de colaboración, ni tampoco estaba interesada en hacerlo", nos contaba Carlos, un dirigente del Partido Obrero que acompaño en esos días.(Carlos, comunicación personal, 26 de febrero de 2015) La Central de Trabajadores Argentinos (CTA $)^{11}$ a nivel local estuvo desde un principio apoyando la lucha de los desocupados, en el plano legal y hasta en la colaboración de tareas mínimas de mantenimiento logístico.

El empleo digno se fue transformando en el principal reclamo de la UTD, junto a un subsidio que permitiera "la edificación de una sociedad sin miserables ni opulentos; sin menesterosos y sobre-enriquecidos, sin hambrientos de días de aguantar sin nada ni derroche y acaparamiento especulativo" ${ }^{12}$. Más de 500 desocupados se movilizaron el 26 de octubre y fueron recibidos por ediles del Concejo Deliberante y por el propio intendente; se les prometió ingresar en planes de trabajo y ampliar el cupo del PROAS (planes sociales provinciales) (La Nueva Provincia, 4 de octubre de 1995, p. 9). Finalmente, la conflictividad se resolvió momentáneamente cuando se iniciaron gestiones para que la UTD pudiera continuar su actividad junto con los desocupados en unos galpones abandonados de la ex Estación Ferrocarril Noroeste. En enero de 1996, otro grupo de desocupados disidente realizo un segundo intento de acampe en la plaza, pero fue abortado por la policía y el propio intendente (La Nueva Provincia, 28 de noviembre de 1995, p. 8) $)^{13}$.

El epílogo de esta primera etapa fue la promesa de continuidad con los planes provinciales, que logró cierta quietud temporaria de la organización (La Nueva Provincia, 28 de enero de 1996, p. 6) ${ }^{14}$. Una funcionaria de la UCR de ese entonces nos comentaba en una entrevista: "El municipio comprendió la necesidad de trabajar con los desocupados tempranamente e inclusive de administrar los primeros planes sociales, algunos provinciales y otros locales, conteniendo la conflictividad" (Verónica, comunicación personal, 14 de julio de 2016). A partir de esos años se articularon proyectos con el gobierno municipal, como la fabricación de mosaicos y bloques, y se procuró no acentuar las disputas. El grupo de desocupados ligado a la UTD terminó llevando a cabo un proyecto de construcción de ataúdes y otro de cordones cuneta hasta el año 1999, con la colaboración del Municipio y de Cáritas. ${ }^{15}$ Sin embargo, estos proyectos fracasaron, y sectores importantes de desocupados se retiraron de los microemprendimientos, "ya sea por problemáticas internas, de organización, por los vicios personales o por falta de ayuda económica", como nos comenta Emiliano dirigente de la CTA que acompaño estos procesos (Emiliano, comunicación personal, 9 de marzo de 2015). En muchos casos, la excesiva dependencia del Estado generó un desgaste permanente en las cooperativas debido a solicitudes salariales impagas o condiciones de trabajo incumplidas, que tendían más a la autoexplotación que al reparto igualitario de las horas de trabajo. 


\section{La Corriente Clasista y Combativa (CCC): aspectos generales de SU organización}

La Marcha federal en 1994 fue uno de los “trampolines" que impulsó el crecimiento del Partido del Trabajo y el Pueblo (PTP) (expresión política electoral del Partido Comunista Revolucionario -PCR-) tanto a nivel nacional como a nivel local, con una experiencia política acumulada en los diversos "estallidos sociales" nacionales (Romero Wimer, 2013). Si bien el desarrollo de la CCC experimentó una mayor efervescencia luego de 2001 en Bahía Blanca, su incursión en el movimiento de desocupados databa ya del año 1995. También acompañó a los trabajadores agremiados al petróleo y gas en diversas circunstancias cuando hubo despidos. Francisco, uno de los dirigentes de la organización nos comentaba que:

Las grandes manifestaciones de 2001 y 2002 van a encontrar a una CCC local apostando a lograr una convergencia entre el movimiento de docentes y familias indignados por la situación económica y política y el movimiento de desocupados, vinculando sus problemáticas a fin de generar un polo más amplio de liberación nacional ( Francisco, comunicación personal, 8 de abril de 2015).

La llegada a Bahía Blanca de algunos de los militantes del PCR-PTP que provenían de las experiencias del conurbano marcó un antes y después en la constitución de la CCC a nivel local. Si bien se caracterizaba a Bahía Blanca como una ciudad con un gran potencial para la lucha de masas, se entendía que el peso del aparato del Estado y sus múltiples alianzas con diversos organismos mediáticos, militares, empresariales y eclesiásticos ahogaba históricamente cualquier tipo de proceso de organización incipiente en la ciudad. De esta manera, la constitución de la CCC- Bahía Blanca se ligó en un primer momento a los sectores estudiantiles y a los sectores populares marginales; en este proceso se destaca la constitución de ferias culturales. A partir de 2000, como nos explicó un referente de la CCC llamado Jorge, "se afianza una línea nacional que buscaba avanzar territorialmente con la mira puesta en las necesidades básicas de la población"(Jorge, comunicación personal, 30 de marzo de 2015). Las discusiones que se daban en las incipientes reuniones comenzaron a calar profundo en los vecinos de barrios con extremas necesidades, como Villa Caracol y Maldonado, en la periferia de la ciudad.

Lentamente se fue llevando a cabo una metodología de trabajo que se extendió hacia los años 2002-2003 en treinta barrios (entre los que estaban Villa Caracol, Maldonado, Villa Nocito, Noroeste, Avellaneda, Cooperación, Richieri, 5 de abril, Punta Blanca, Grunbein, 9 de Noviembre). Francisco nos relató que se realizaban reuniones asamblearias para discutir las actividades a realizar-talleres, ferias y trabajos barriales-, las cuales buscaban restituir el trabajo y consolidar una organización política frente a la pobreza.

El ingreso a la organización por parte de muchos de los desocupados de las barriadas populares tenía un fuerte componente estructural basado en la necesidad alimentaria. Esta necesidad implicaba, además, una "bronca social", y, por otro lado, el "gusto por hacer política". Decidir y cuestionar era lo que incentivaba a adscribir a la organización. En las reuniones se planteaban discusiones políticas que invitaban a vincular la realidad nacional con la internacional. El diario del PCR $(H o y)$ se repartía entre los desocupados "pero nunca fue un elemento aglutinante y se entregaba sin imposiciones a la organización, solo como material para aquellos que podían leer", según nos relató Francisco.

El formato básico de trabajo en Bahía Blanca eran los proyectos productivos, fundamentalmente organizados por las mujeres. Las actividades económicas que se dieron por un convenio con la Municipalidad estaban centralizadas en un solo espacio, ubicado en pleno macrocentro de la ciudad, y eran controladas por un grupo heterogéneo de delegados en distintos emprendimientos: panaderías, talleres de costura, soldadura, carpintería y fábricas de cercos recuperables. Las mujeres tenían un rol preponderante en todas las actividades de la CCC, al punto que muchas de ellas se convirtieron en referentes barriales, como fue el caso de Rosario, una exintegrante de la CCC que entrevistamos (Rosario, comunicación personal, 6 de abril de 2015

Existía en la CCC una mesa general que respondía a los referentes del partido, quienes basaban sus decisiones en el centralismo democrático. Esta situación, sin embargo, no fue percibida de la misma manera 
por las bases: algunas integrantes, como Rosario, manifestaron que percibían que "no se les dejaba decidir demasiado, ni tomar vuelo propio". Aun así, el mecanismo de trabajo para tomar cualquier decisión fue siempre el asambleario. Cada barrio enviaba a su delegado, aunque no eran "delegados formales” pero sí de hecho. Las delegadas barriales se elegían a mano alzada y tenían una revocación inmediata, de una reunión a otra. Como explica Francisco: "Nunca se escribió un estatuto, aunque sí existieron reglamentos, pero el funcionamiento de estas organizaciones se basaba mayormente en la conducta de sus integrantes, su trabajo y su conciencia política”.

Con la lucha por los planes sociales, que se convirtió en el objetivo más importante en términos económicos de la CCC, se dieron debates locales que intentaron ganar cierta autonomía respecto del partido, para lograr efectivizar un mecanismo de organización, lucha, obtención de planes y regulación, que posibilitara extender la agrupación e incorporar las discusiones políticas de fondo. La CCC logró organizar, con posterioridad a 2003, unos 400 planes aproximadamente, con 600 trabajadores organizados. Los planes sociales eran valorados como "conquistas de una lucha en el terreno de las clases dominantes y el Estado, que siempre se encuentran a diario para disputarte lo organizado, al igual que la cúpula de la Iglesia y los punteros" (Francisco, comunicación personal, 8 de abril de 2015). En la CCC se fueron dando algunos debates que llevaron a aceptar la idea de la contraprestación, planteo que se dio en el marco de la discusión sobre el trabajo digno.

La obtención de los planes o de mercadería se lograba a través del mismo mecanismo que utilizaban otras organizaciones de desocupados: la de ocupar o manifestarse en determinados recintos púbicos (como el Concejo Deliberante o el Municipio). Durante el gobierno de la Alianza estuvieron bajo el poder de las propias organizaciones, pero luego de 2002 eran regulados por cada municipio. Lo mismo sucedió con las cajas alimentarias. Como explicaba Jorge: "Para obtenerlas se utilizaba la personería de Amas de Casa del País, y las responsables de su cobro y distribución eran tres mujeres elegidas por los beneficiarios”.

Toda la mercadería recibida y la asignación de planes se controlaban a través de un mecanismo de puntaje, luego las compañeras referentes realizaban un reparto equitativo según lo acordado en asamblea. Los referentes de la CCC hablaban de "una batalla ideológica muy importante que debía realizarse con los compañeros, de autocontrol, que el compañero sepa que es por una cuestión de solidaridad, porque hay otra persona atrás que lo está necesitando" (Jorge, comunicación personal, 30 de marzo de 2015). Esta cuestión del puntaje formó parte de una estrategia para elevar el grado de conciencia de los involucrados, pero también fue un mecanismo de control de la propia organización, que incidía en las formas de participación y en el compromiso real que manifestaban los participantes. El puntaje máximo se obtenía al participar de una marcha o una movilización, poniendo el cuerpo en determinados actos o manifestaciones, lo que mostraba a propios y ajenos la fuerza de la agrupación. Luego, estaban otras acciones que tenían menos puntaje. Al finalizar un período determinado se contabilizaban los puntajes y se asignaban determinados beneficios. El control en la distribución de los alimentos en un barrio específico no siempre fue transparente, y se han dado casos aislados en los que se utilizaron de manera clientelar, o en los que los propios militantes de la organización los repartían entre familiares.

Si un conflicto de esas características podía tratarse en un marco asambleario, se hablaba con la persona, se intentaba humanizar el conflicto y no castigarlo. La búsqueda del reconocimiento del error formaba parte de ese proceso de reconversión, que para los dirigentes del movimiento implicaba revertir prácticas burguesas instaladas con fuerza entre los sectores populares. Las propias bases también coincidían en términos generales con el método de puntaje. Se planteaba que el sentido de justicia de los sectores populares los llevaba perfectamente a reconocer el equilibrio entre la obtención de ganancias y el esfuerzo realizado. Este pensamiento formaba parte también de la concepción tradicional de "recibir por lo trabajado". Aun así, se reconocían fisuras en su tratamiento, dificultades que surgían cuando los integrantes de la organización no podían realmente participar de acciones colectivas y podían ser juzgados arbitrariamente. 


\section{El Movimiento Territorial de Liberación (MTL) en Bahía Blanca}

El 25 de septiembre de 2001 se realizó una presentación pública del MTL-Bahía Blanca en la Plaza Rivadavia para dar a conocer sus propuestas e integrantes. Su principal proclama era la de defender los derechos mínimos del artículo 14 bis de la Constitución Nacional, solicitando a las autoridades municipales y al Concejo Deliberante la creación de fuentes genuinas de trabajo, la suspensión de despidos, la creación de un seguro de desempleo, y la formación y fiscalización de bolsas de trabajo con el fin de evitar manipulaciones. Por otro lado, se explicitaron los proyectos de reestatización de la empresa de aguas corrientes, la construcción de barrios populares y acceso al parlamento local (La Nueva Provincia, 26 de septiembre de 2001, p. 6). Se percibía que las privatizaciones y las políticas gubernamentales habían llevado a un nivel de desocupación en Bahía Blanca con porcentajes muy altos en comparación al resto de la provincia de Buenos Aires, con grandes asentamientos y bolsones de pobreza. Estas nuevas villas se relacionaban con los "saltos de la burguesía” y eran la contracara del progreso de las inversiones locales, que mostraban cierta incidencia en el empleo local solo cuando ocupaban personal temporario para la construcción de las plantas del Polo Petroquímico y la central Termoeléctrica. La idea del MTL era darle "un contenido político a la lucha, en todos los terrenos, darle formación, orientación y contenido a la lucha del pueblo, para que esa lucha no se quede en un estado asambleario" (Juan, comunicación personal, 11 de julio de 2016).

La relación con el Partido Comunista (PC) era muy importante, pero en ningún momento se presentó como un espacio de intervención partidista. Se partía de un desarrollo importante del movimiento de izquierda popular en Bahía Blanca, que se ligaba, como cuenta Alejandro, un joven exmilitante del MTL,

a las luchas estudiantiles y docentes contra las leyes de educación menemistas, el recorte presupuestario y la fragmentación compulsiva del salario, y se unía a la lucha por los derechos humanos y los primeros juicios por la verdad, y a las luchas de los vecinos por los servicios básicos y condiciones dignas de vida en los barrios (Alejandro, comunicación personal , 11 de abril de 2015).

En todo ese proceso, las luchas democráticas aceleraban sus disrupciones frente al avance represivo del gobierno aliancista, donde el gran ausente, según la caracterización del MTL, era la dirigencia sindical. Para una mayoría dentro del MTL, el sujeto central ya no era la clase obrera industrial, "porque los agredidos por el modelo capitalista eran muchos más, se hablaba de un sujeto popular no clasista...del sujeto pueblo como sujeto revolucionario" (Laureano, comunicación personal, 30 de abril de 2015).Esta lectura explicará entonces las acciones y propuestas metodológicas de intervención que imprimieron un sello característico al MTL.

El análisis partía de considerar que el hombre "entraba en crisis" cuando se convertía en un desocupado, porque ya no podía mantener a su familia, y la mujer adquiría diversos roles que la colocaban como "nuevo sostén". La organización debía "asesorar en términos psicológicos a sus integrantes, con el objetivo de establecer una norma, con el objetivo de construir una etapa de transición que rompiera con la dispersión, el aislamiento y el individualismo que generaba el proceso de desocupación". Para resolver esa situación se colaboraba con propuestas de trabajo que superaran el mero pedido de ayuda al Estado y que permitieran crear lazos de solidaridad y compromiso alrededor de proyectos y actividades productivas. Los proyectos autogestionados buscaban el compromiso del Estado para comprar la producción y colocarla en el mercado. También se solicitaba permiso para realizar "ferias francas". La cuestión de la batalla cultural era retomada por el MTL, como una forma de acrecentar la conciencia política de las clases populares.

Los planes sociales fueron parte de la vida cotidiana de las organizaciones, pero hubo diferencias respecto de las formas en que fueron considerados por la propia base. En los años 1995-1997 los planes sociales todavía generaban resquemor y se continuaba con el reclamo por trabajo genuino, como parte de la idiosincrasia de los propios desocupados, antiguos trabajadores con experiencias sindicales. Para los años 2000-2001, los cambios en el trabajo y las formas de empleabilidad propiciaron que un conjunto de jóvenes estuvieran desempleados 
estructuralmente con pocas posibilidades de ser contratados. En general, el MTL tuvo bajo su órbita muy pocos planes sociales, mientras que su fuerza se concentraba en la realización de actividades productivas propias, que les permitieran autofinanciarse y colaborar con los militantes. Por otro lado, se reclamaban bolsones de mercadería o empleo en las obras, con la idea de no caer en la tentación de ser intervenidos por el Estado, o de generar vínculos de dependencia, como nos contaba Juan. La discusión principal, por lo menos entre los referentes, se planteaba en términos de generar trabajo genuino, "porque se sabía que existía la posibilidad y que era necesaria también porque uno levantaba el nivel de expectativa de los compañeros, no era solamente quedarse con el bolsón y salvar el momento. El plan era una humillación" (Manolo, comunicación personal, 11 de abril de 2016). Pero esto también chocaba con la necesidad de resolver la urgencia diaria, lo que generaba crisis y tensiones frente al proceso de construcción de conciencia política; "el plan te genera resolver lo cotidiano, había una disputa tremenda, si bien teníamos claro el daño que nos íbamos a hacer, también tuvimos clara la necesidad de aceptarlo y pelearlo", como expresaba Juan en la entrevista.

Esta organización de desocupados fue partícipe de la conformación de cooperativas en el territorio. Una de las más grandes, tanto por sus dimensiones como por la cantidad de militantes del MTL con que contaba, fue la Cooperativa de Pavimentación, ubicada en Bahía Blanca. El MTL logró una construcción territorial en los barrios Caracol, Miramar, Maldonado, Villa Perro, Noroeste y en Ing. White con la idea de propiciar una organización más amplia de desocupados. En todos estos lugares había delegados; llegó a contar con 30 en los años posteriores a 2003. Se realizaban asambleas entre los desocupados de los barrios, con los "cabecillas de la organización"; se decidían las actividades y acciones de protesta, y la forma en que se llevarían a cabo.

El MTL tuvo una capacidad de movilización de unas 250 a 300 personas y sus primeras solicitudes fueron de subsidios y planes de empleo a la Municipalidad, hacia el año 2000. Participaron en decenas de marchas y manifestaciones, y tuvieron una notable capacidad de asimilar y solidarizarse con diversas manifestaciones populares de la ciudad, desde reclamos por el suministro de agua, acompañar a los afiliados de APYME o los trabajadores de la construcción, hasta marchar contra la contaminación del Polo Petroquímico o por los derechos humanos. Al igual que otras organizaciones de desocupados, el MTL va a amalgamar al sector estudiantil con las capas más pobres de los sectores de trabajadores desocupados.

Sin embargo, la organización tampoco escapó a los problemas internos; tuvo su mayor fractura durante un piquete decidido a nivel nacional en 2002, por el que muchos militantes resultaron reprimidos y procesados. Esta situación significó el deterioro orgánico del MTL, y el éxodo de muchos militantes que se decantaron por otras opciones políticas. Por otro lado, la infiltración del propio Estado, las ambiciones personales y las prácticas conflictivas entre movimiento y partido empeoraron las relaciones sociales e hicieron que la organización comenzara a disolverse, por lo menos a nivel local. El diagnóstico de las consecuencias de declinación del MTL por parte de la dirigencia aludía a un problema de organización y conciencia política, como nos marcaba Juan. Los miembros de base entrevistados, como Alejandro y Laureano (que decidieron retirarse del MTL), fueron muy críticos con la organización y señalaron los límites al movimiento de desocupados, a saber: cierto método clientelar en las decisiones y en el uso de las asambleas; la imposibilidad de generar una perspectiva política que fuera más allá del reclamo de mercadería, y la falta de una administración y de una organización independiente del movimiento de desocupados.

\section{Polo Obrero (PO): su desarrollo histórico en Bahía Blanca}

El Partido Obrero, de orientación trotskista, fue fundado en 1964 en la Argentina y ha formado parte de la Coordinadora por la Refundación de la Cuarta Internacional Marxista hasta la actualidad. En la década de 1990, Bahía Blanca agrupaba a un grupo poco numeroso de militantes, que habían realizado acciones en el movimiento estudiantil y obrero, y que venían de ser perseguidos por la dictadura militar. Muchos de sus miembros habían sufrido directamente los embates de las privatizaciones. 
El PO fue una de las primeras organizaciones, junto al PC y el PCR, en visibilizar la problemática de los desocupados. A pesar de que algunos autores señalan que se interesaron tardíamente por este movimiento como sujeto político factible de organizarse (Svampa y Pereyra, 2003), colaboraron en su lucha, aunando los esfuerzos por incluir las demandas de los desocupados junto con las del movimiento ocupado.

En 1995, según algunos de sus propios cuadros políticos como Carlos, líder del Partido Obrero local en esos años, "el movimiento de desocupados era un movimiento social incipiente, con un grado de organización con muy poca autonomía y en general muy ligado a la experiencia sindical y barrial de sus integrantes" (Carlos, comunicación personal, 26 de febrero de 2015). Por eso, la continuidad con los métodos de lucha de las organizaciones obreras de viejo cuño y de las experiencias de protesta fomentistas. La caracterización que realizaba el PO del movimiento de desocupados, principalmente del que aparecía en 1995, era la de

un movimiento heterogéneo con el serio problema de atraso de la clase trabajadora en términos de organización independiente; un sector con debilidades, al estar disperso y fragmentado en múltiples cuentapropistas y representarse desamparado frente a las burocracias sindicales (Mario, comunicación personal 13 de marzo de 2015).

El Polo Obrero, como una agrupación ligada directamente al Partido Obrero, nace con mayor fuerza a fines del año 2000, con similares características que las formaciones a nivel nacional. La intervención principal, que se había iniciado en 1995, no tuvo continuidad en Bahía Blanca, pero sí se dio con fuerza en Neuquén y Gran Buenos Aires. A nivel regional, el Polo Obrero se había extendido en Coronel Suarez con el apoyo a los despedidos de la fábrica de zapatillas Gatic, y en Carmen de Patagones, donde el aumento de la desocupación contrastaba con un descenso notable en el desarrollo agrario. En el año 2000 se realiza un encuentro inaugural en un salón de la Asociación Empleados de Comercio, en la que participó el dirigente nacional Néstor Pitrola. Participaron también los referentes nacionales del MTL, un sector de desocupados de Mar del Plata, y algunos sectores desocupados bahienses.

El Polo Obrero se desarrolla rápidamente con la idea principal -como expresa uno de sus protagonistas llamado Cristian- "de organizar a los desocupados y unirlos a los reclamos del movimiento ocupado sindical” (Cristian, comunicación personal, 4 de marzo de 2015). Su idea, al igual que la del partido, era articular a nivel nacional con los otros polos obreros y avanzar en el desarrollo de una organización más amplia. La experiencia territorial implicaba una nueva forma de intervención del partido en sectores a los que se caracterizaba como plagados de contradicciones. La contradicción principal que se planteaba tenía que ver con la insistencia en paliar la necesidad material sin plantear la discusión política.

Se organizaron comedores y merenderos siempre apoyados con referentes barriales con los que se había establecido un contacto. La comunicación con el barrio era diaria. La lucha, al igual que en las demás organizaciones de desocupados, comenzó con la solicitud al Municipio de bolsones de mercadería, harina y herramientas para determinados proyectos. Como nos cuenta Cristian, de amplia trayectoria barrial: "Logramos acceder a algunos planes, pero en general el partido no tenía una mirada positiva sobre esos 'beneficios".

El Polo Obrero va a insistir en que la obtención de un plan social era parte de una lucha "arrancada al Estado", que tenía que servir para formar cuadros políticos, para concientizar sobre el papel que cumplía la resistencia y la acción política en la consecución de esos resultados. Así lo expresaba Ramiro, militante de base, en relación al plan social: "En última instancia, se reivindicaba la búsqueda del trabajo genuino y no de paliativos que liquidaran la organización” (Ramiro y Cecilia, comunicación personal, 18 de marzo de 2015). Para los miembros del Polo Obrero, la contraprestación laboral a partir de un subsidio o de un plan era un arma de doble filo que el poder político utilizaba para su propio beneficio. La ley obligaba al desocupado a prestar servicio -en general, de mantenimiento- en una repartición municipal, por cuatro horas diarias. Esta prestación se realizaba en la precarización absoluta y en condiciones laborales que no propiciaban la motivación ni la solidaridad. 
Según Mario, los barrios donde se había logrado realizar un trabajo comunitario basado en una copa de leche fueron Saladero (White), Stella Maris, Villa Nocito, Maldonado, sectores del sur, Villa Delfina -entre otros-, y en algún momento Cerri (Mario, comunicación personal, 13 de marzo de 2015). Con la harina que se solicitaba al municipio se solventaban los comedores para la realización de panificados. Nunca se entregaron bolsones a las familias; se impuso la idea de compartir todos los bolsones y no distribuirlos. Todo se decidía asambleariamente, desde la forma, el destino, la compra de insumos y los faltantes, hasta qué destino tendrían las ganancias por su venta. En muchos casos los excedentes se destinaban a la comida de los chicos que asistían al comedor, o se repartían entre los presentes. Según el Polo obrero, los partidos políticos como la UCR o el PJ utilizaban las sociedades de fomento como espacios de contención social del conflicto a través de mecanismo clientelares y de cooptación política, como la entrega de mercadería a cambios de favores electorales, o de subsidios sociales.

El Polo Obrero estaba en contra de tomar listados sobre las familias desocupadas cuando se iba a una movilización. Para ellos se debía dar el compromiso como algo natural, algo que expresara el sentir del propio desocupado y no como un acto de compromiso hacia la organización. Por otro lado, criticaban indirectamente a otras organizaciones que planteaban la consigna de "el que luche, come", y sus métodos de impulsar la participación.

Mayoritariamente participaban mujeres en la organización. Carlos nos cuenta que se hablaba de "un "factor cultural que explicaba que los varones habían sido colocados en una situación "vergonzosa" al no tener empleo y no poder mantener a sus familias, una idea impuesta por la cultura hegemónica machista”. De los talleres para los jóvenes había uno de música y aprendizaje de instrumentos, panificados y trabajos básicos en los que participaban también adultos/as; también se hacían festivales en jornadas concretas como el 24 de marzo o el 1 de mayo, en clave de resistencia.

Cristian, en su relato de experiencia barrial, nos decía que en todas las reuniones se insistía con la lectura y la discusión política. Si bien se le daba mucha importancia a lo oral, ya que se observaban de antemano las dificultades en el hábito de lectura de la población en su mayoría, se le daba tratamiento a la Prensa Obrera. Las lecturas podían ser en grupos acompañados de algún militante que daba los lineamientos políticos principales de la semana para "orientar" su interpretación. Sin embargo, Mario expresaba que "la lectura era una comprensión particular para cada uno y que la Prensa Obrera tiene textos difíciles, que cuesta comprenderlos, que necesitan que alguien la explique, porque si no se entiende inacabadamente el planteo principal".

El Polo Obrero tuvo una participación notable en el tema de las viviendas urbanas para los barrios marginales. La problemática del acceso a la tierra y vivienda se incrementó cuando con posterioridad a 2003 hubo una serie de denuncias en el Instituto de la Vivienda, el cual fue finalmente fue intervenido por fraude. Cristian comentaba en su entrevista que un grupo de militantes del Polo se acercó a distintas familias de barrios con necesidades habitacionales; entre ellas estaban Napal, Don Bosco, 9 de noviembre, Grunbein, por lo que decidieron darle forma a la idea de un congreso de la vivienda hacia el 2007.

Con posterioridad a las experiencias desarrolladas y pasado un tiempo de análisis y reflexión sobre lo realizado, algunos de los militantes entrevistados renegaban de su enfoque y de su perspectiva estratégica para actuar con los sectores populares. Cristian, quien aún permanece en el Partido Obrero, veía como una seria limitación que "el partido no haya podido generar militantes políticos interesados en una perspectiva más amplia, que vislumbrara la posibilidad de participar en un espacio político por el socialismo". Se observaba que la militancia se les imponía por fuera y que su verdadero motor de acción no era una serie de ideas alrededor del partido sino la indignación. Esto se contraponía con aquel obrero clásico de los años 60 y 70 , que tenía estabilidad en el empleo y que había logrado grandes conquistas apostando por la lucha dentro del ámbito sindical y de forma clasista. Por otro lado, la imposibilidad de organizarse también se debió "a que el gobierno cooptó el movimiento junto con sectores de la burguesía para evitar la conflictividad social”, como nos explicaba Ramiro. 


\section{LA CONSTITUCIÓN DEL FRENTE DE TRABAJADORES DESOCUPADOS Y OCUPADOS BAHÍA BLANCA EN LUCHA (2001- 2003)}

En los años 2000 y 2001, la crisis económica a nivel nacional repercutió en la merma en la producción industria local y en la falta de inversiones hacia el polo petroquímico, cuya parálisis se notó finalizada la construcción de las nuevas plantas (La Nueva Provincia, 12 de enero de 2000, p. 6). En este contexto se reactivaron los conflictos internos dentro del sindicato de la UOCRA. Por esos años nació una nueva organización de desocupados, que estableció su accionar en las denominadas marchas del silencio por la dignidad y el trabajo, de las que participaron mayoritariamente desocupados y trabajadores de la construcción opositores a la conducción ganada por Raúl Rubino (Lista Blanca de la UOCRA) en 1998. Reclamaban falta de oportunidades de reinserción laboral en los emprendimientos iniciados en los últimos años, principalmente en el sector industrial, y denunciaban el manejo burocrático de la bolsa de trabajo sindical ( $L a$ Nueva Provincia, 30 de septiembre de 2000, p. 4). Esta organización se llamará Asociación de Desocupados de la Industria de la Construcción Bahía Blanca (ADICBBA).

Según uno de los participantes de esta organización, el abogado Bruno, esta asociación de desocupados "intentó generar un movimiento más amplio, que les permitiera presionar por una ley de emergencia ocupacional y el fomento a la creación de puestos laborales estables" (Bruno, comunicación personal, 10 de mayo de 2016). Además, el movimiento abogó por el otorgamiento de créditos, subsidios a los desempleados (de 400 pesos) y exenciones impositivas (La Nueva Provincia, 7 de enero de 2001, p. 4). Esta agrupación tuvo en claro que los cambios solo se podían originar a través del objetivo político de obtener el sindicato, luchando internamente por un lugar en la dirección. Durante los años 2000 a 2003 se desarrollaron una serie de conflictos -tanto con las empresas como entre las facciones internas dentro del sindicato- por la conducción de la UOCRA, que terminaron con graves incidentes luego del 31 de julio de $2001 .^{16}$

En el año 2001, la situación nacional y provincial llegaba a un punto de saturación en medio de un proceso de ebullición de la conflictividad obrera. En el plano de los estatales, la conformación de una agrupación de docentes disidentes de la conducción del sindicato de SUTEBA llevó al engarce con un incipiente movimiento de padres, madres, estudiantes y docentes autoconvocados, como una forma de presionar al poder político y al propio sindicato (liderado por la lista Celeste) para que asumiera un posicionamiento frente a la gravedad del ajuste. ${ }^{17}$ Esta situación implicó que en julio y agosto de 2001, luego de las medidas de Lopez Murphy, se generara un conjunto de movilizaciones importantes y multitudinarias contra el gobierno de Buenos Aires y contra el gobierno nacional, que fueron denominadas por la memoria popular como Escuelazos. Estos episodios fueron la expresión de un descontento popular que se formulaba más allá de las manifestaciones docentes. Constituyó una respuesta de los trabajadores estatales, del movimiento asambleario por escuelas, de la participación de padres y madres autoconvocados preocupados por la situación de la educación, pero también de la situación política del país, que prendió efectivamente en las masas y que permitió canalizar la protesta de miles de bahienses. Puede caracterizarse esta experiencia como la antesala del Argentinazo en Bahía Blanca (EcoDías, septiembre de 2011, p. 3).

Una de las consignas que fogoneaba a los docentes era la idea de unidad de los trabajadores, que también era compartida por estatales, la CTA y los propios desocupados. Este movimiento conectaba con la lucha de los sectores más empobrecidos de las clases medias y populares, acompañados de un sector de la pequeña burguesía enrolado en APYME. Sin embargo, no tuvo el acompañamiento de sectores sindicales industriales o comerciales, ni tampoco de la clase obrera más combativa, expresada en los trabajadores de la construcción o en los petroquímicos.

Es en este período que nace la multisectorial Bahía Blanca en Lucha, una organización que se fue creando a partir de asambleas interbarriales entre trabajadores ocupados y desocupados, integradas por desocupados de la industria y la construcción, docentes, estudiantes y vecinos de los barrios Maldonado, Delfina, Loma Paraguaya, Bordeau, Colonia Ferroviaria y la localidad vecina de Gral. Cerri. La vieja UTD, que volvía a 
renacer en aquellos tiempos, tuvo una participación importante en la conformación de esta organización. Uno de los integrantes de Bahía Blanca en Lucha expresaba: "Ante la masificación de los planes sociales, este sector se plantaba con fuerza como una línea dura contra la aceptación del asistencialismo” (Andrés, comunicación personal, 13 de abril de 2015). El movimiento tuvo una corta duración pero fue muy intenso. Su participación en acciones concretas estuvo ligada principalmente a las acciones de la CTA, a las agrupaciones de docentes independientes y a las organizaciones de desocupados, obreros de la industria (fideeros, construcción) y trabajadores estatales (salud y educación).

Una de las consignas más importantes de Bahía Blanca en Lucha fue la de unidad de las luchas. Esta proclama resumía en una frase toda una política de alianzas entre fuerzas sociales diversas, que buscaba resignar algunas de las diferencias programáticas entre las mismas con el fin de generar una resistencia con el mayor número de actores posibles. A su vez, alertaba sobre las consecuencias de profundizar en las diferencias internas de la clase obrera, que solo llevaban a una atomización del movimiento y a "un callejón sin salida".

En sus primeras reuniones, en noviembre de 2001, la organización llamaría a una movilización en diciembre para la realización de una olla popular. El 20 de diciembre a la madrugada se congregaron unas 300 personas en la plaza Rivadavia. Como cuenta Carlos, "la gente se autonvocaba, algunos con cacerolas, enfrentando el estado de sitio decretado por el ejecutivo nacional" ${ }^{\prime 1}$. La movilización se congregó frente al Palacio Comunal, lo que sirvió para aunar criterios de qué hacer en los días siguientes. Una muralla policial impedía el paso hacia el Palacio Municipal. En los días previos hubo una salida masiva de personas de los barrios hacia distintos supermercados bahienses, como la Cooperativa Obrera, Casa Tía, Disco y Walmart que fueron presionados para entregar alimentos. El 20 de diciembre desde las 8 de la mañana, docentes, estudiantes, desocupados, artistas, vecinos y miembros de partidos políticos se reunieron en la intersección de calles de acceso a la ciudad, con un piquete garantizado por la CCC y desocupados del barrio Maldonado y Villa Caracol. A partir de las 10 horas, ese conjunto numeroso caminó hacia la plaza Rivadavia para unirse a la concentración que venía de Brown y Montevideo, en la que participaron vecinos del barrio 1 de Mayo y el MTL. En la plaza Rivadavia, además de estas organizaciones, se concentraron desde sus propios barrios la UTD, Bahía Blanca en Lucha y Docentes Indignados. Sobre el mediodía se realizó una olla popular. Expresaron su descontento con pancartas reclamando "por trabajo, alimentos y medicamentos para los más necesitados" 19 , y se escucharon algunos discursos. Al igual que el día anterior, el dispositivo policial que incluía además al Ejército, la Prefectura y servicios de inteligencia se encontraba expectante frente a la situación. El 21 de diciembre unas tres mil personas fueron a solicitar alimentos a la comuna. Debido a una red de contención social dispuesta por el municipio, empresas privadas y ONGs se garantizó la entrega rápidamente, sin que se produjeran "conflictos de envergadura" (Romero Wimer, 2013).

Días posteriores, Bahía Blanca en Lucha conformaría una comisión para participar de las Asambleas Nacionales de Trabajadores Ocupados y Desocupados en diciembre de 2001 y febrero de 2002, como nos informó María, una de sus participantes (María, comunicación personal, 18 de abril de 2016). Entre las resoluciones de la Asamblea Nacional Piquetera realizada en febrero, se decidió realizar piquetes en todas las refinerías del país por 24 horas..$^{20}$ Esta decisión, acatada por Bahía Blanca en Lucha y apoyada por el MTL, un sector del Polo Obrero y algunos docentes indignados, generó una de las represiones más importantes en la historia de Bahía Blanca (Pagina 12, 9 de octubre de 2004, p. 4), con un saldo desfavorable en términos de continuidad de la lucha ${ }^{21}$ y con planteos estratégicos y tácticos que anunciaron divisiones profundas en la izquierda bahiense. El procesamiento fue muy largo y persecutorio con una reacción disciplinadora contundente. La lucha por el desprocesamiento fue una manifestación más de la unidad de diversos sectores para lograr detener la criminalización de la protesta. ${ }^{22}$ La CTA y otros sectores organizaron campañas a nivel nacional, provincial, y local; juntaron firmas, recurrieron a abogados, e intentaron acrecentar la solidaridad con otros grupos. Muchas organizaciones políticas apoyaron la causa y la convirtieron en una bandera de lucha por muchos años, no solo por los 55 estudiantes y trabajadores procesados por la causa Eg3, sino 
también por los 57 desocupados de la construcción procesados en la causa Profertil. ${ }^{23} \mathrm{El}$ movimiento de desocupados local quedó resentido luego de la dura represión de febrero de 2002. A nivel nacional, junio de 2002 tendrá un desenlace parecido, con la aceleración de las elecciones por parte de Duhalde. Las alianzas sociales a que dio lugar el movimiento docente y los "escuelazos" en Bahía Blanca continuaron siendo un eje de resistencia durante todo ese año y el siguiente, hasta que la situación económica y política comenzó a reactivarse, aunque mantuvo altos índices de precarización laboral e informalidad (EcoDias, marzo de 2002, pp. 3 y 4; EcoDias, abril de 2002, p. 3).

Luego de la represión y de la merma de militantes, Bahía Blanca en Lucha se volcó a la convocatoria de movilizaciones y a la lucha en los barrios; ${ }^{24}$ elaboró un petitorio específico con demandas de los trabajadores desocupados y ocupados (que incluía docentes, estatales, ferroviarios, trabajadores de sanidad, trabajadores expulsados de la lanera Torello, Barrita de Oro, recolectores de Cliba y colectiveros), estudiantes, jubilados, y ahorristas. Las demandas planteadas apostaban al trabajo genuino, la aplicación de un plan de emergencia laboral, beneficio doble de los planes dentro del matrimonio, un plan de emergencia alimentaria y sanitaria, reactivación de las empresas o funcionamiento bajo control obrero, sueldos de los políticos equivalentes a la canasta básica, pesificación de las deudas y reparto de tierras ociosas. ${ }^{25}$ Sin embargo, Bahía Blanca en Lucha fue perdiendo terreno hasta dividirse internamente durante el gobierno kirchnerista. Hacia 2003, las alianzas políticas de los partidos burgueses, el rearmado del peronismo y una situación económica que preanunciaba muchos cambios fueron delineando los futuros reclamos de los desocupados: la administración de los planes sociales, ayuda alimentaria y cobertura de salud mínima.

\section{Conclusiones}

En este artículo se brindó una breve caracterización de las organizaciones de trabajadores desocupados durante el período 1995-2003 en Bahía Blanca. La derrota de las luchas obreras sindicalizadas a fines de 1980 daría paso a las reformas de Estado que ejecutó el menemismo y continuó la Alianza. El aumento en la desocupación y la pobreza fue casi inmediato. Así, el año 1995 marcó el inicio de la conflictividad en Bahía Blanca, cuando las consecuencias de ese proceso se plasmaron en una tasa de desocupación del $20 \%$, tres puntos por encima de la tasa nacional. A partir de entonces, el movimiento de trabajadores desocupados comenzó a visibilizarse, acompañado por agrupaciones sindicales y políticas que, con altibajos, conformaron una alianza social junto a otras fracciones sociales (estudiantes, jubilados, obreros de la construcción, docentes, profesionales, estatales). En los años 1997 a 1999 se produjo un leve descenso de la conflictividad social, y las organizaciones de desocupados de tinte localista impulsaron un proceso que fomentó el trabajo en cooperativas con base territorial, lo que determinó una relación conflictiva con el gobierno radical, al punto que dichas cooperativas fracasaron como emprendimientos económicos. A principios de 2000, y hasta mediados del 2001, el incremento general de las luchas convierte al sector de desocupados en una capa social dinámica dentro del movimiento asalariado, que da lugar al desarrollo de una fuerza social de resistencia en la que se conjugaron fuertemente las bases obreras estatales por fuera del sindicato, los sectores desocupados de la construcción, y las organizaciones de desocupados nacientes como el Polo Obrero, la CCC, el MTL y Bahía Blanca en Lucha, cuyos militantes habían capitalizado las experiencias de lucha en los primeros conflictos de desocupados de la década.

La conflictividad de las organizaciones de trabajadores desocupados tuvo una serie de características definidas alrededor de determinados tipos de hechos (manifestaciones y acompañamientos a huelgas generales), con una mayor predisposición al método directo de enfrentamiento y al alto nivel de intensidad en las acciones. La forma de trabajo asamblearia favoreció la articulación de intereses de distintas fracciones sociales en lucha; legitimó posiciones, permitió una dirección colectiva de la lucha y generó participación de las bases. 
Finalmente, el año 2002 verá un nuevo auge de la lucha en las calles, con un sector de desocupados radicalizado, que se enfrentó cuerpo a cuerpo con las fuerzas de seguridad. El resultado fue la derrota y el procesamiento de los desocupados y la retirada de diversas organizaciones de izquierda hacia formas de trabajo sindical y barrial. Con el cambio de gobierno en 2003 se inicia una nueva fase de acumulación capitalista en Argentina, que dará lugar a la conformación de nuevas fuerzas sociales, al tiempo que el movimiento de trabajadores desocupados disminuirá su participación efectiva en el mundo político. Los trabajadores de la educación, de la administración estatal, salud y empresas privadas iniciaron una serie de huelgas sectoriales por el aumento salarial, en un contexto signado por la devaluación y la salida de la crisis económica.

El análisis de las estrategias de acción colectiva no puede desvincularse de la búsqueda de un proyecto político (Pérez Álvarez, 2013) de parte de las organizaciones, el cual, si bien replicaba los parámetros a nivel nacional, tuvo una serie de iniciativas locales que ampliaron el espectro de consensos con otros sectores sociales, principalmente los sectores medios, docentes, trabajadores estatales, jubilados y estudiantes. En este sentido, las estrategias ${ }^{26}$ oscilaron entre una respuesta defensiva a la grave situación económica, pero también ofensivas, en términos de generar una propuesta de organización basada en la solidaridad, el trabajo genuino y la conciencia de clase, a través de la lucha teórica, tanto en el territorio como en los sindicatos y dentro del movimiento obrero general.

Las entrevistas realizadas a los actores sociales (tanto referentes como militantes de base) nos revelan una serie de significantes sociales y culturales que exploran un ethos (una forma común de modos de vida) y reconstruyen su propia experiencia con el pasado. Aparecen con fuerza las ideas de militancia y de pertenencia a una organización política concreta como una práctica de vida. ${ }^{27}$ Se puso de manifiesto la posibilidad de construir un proyecto gestado dentro de un espacio de sociabilidad, a veces barrial, a veces sindical, donde se produjeron encadenamientos sociales que articularon distintos agentes sociales, como espacios de construcción colectiva, permanentemente atravesados por el conflicto y el poder, y un entramado de interdependencias en el que aparecen las dimensiones étnicas, de género y generacionales. ${ }^{28}$

En la ciudad, las organizaciones dentro del MTD se diferenciaron en sus métodos y estrategias de corto y mediano alcance. Existieron, esquemáticamente, tres tipos de agrupamientos, que se combinaron en los distintos estadios de lucha: sindical, político/partidario y territorial. Dentro del movimiento, la acción colectiva disruptiva sirvió a su vez para condensar sentidos e imaginarios que sintetizaban el papel histórico de la lucha de la clase obrera (desde el peronismo y la izquierda). El Movimiento de Trabajadores Desocupados significó la organización de un sector del proletariado que reactualizó los repertorios de acción de las tradiciones obreras y se fundó a sí mismo como agente capaz de crear realidades y resistencias frente a una situación de marginalidad, pobreza y caída económica severa. La subjetividad colectiva que se desarrolló retomó significantes viejos y nuevos, y se amalgamó para dotar de sentido a las formas de participación, los entramados de luchas y los discursos legitimantes. Su incidencia fue fundamental frente a la pasividad sindical y la falta de respuestas por parte del Estado en las barriadas populares

\section{Referencias BibliográficAs}

Ariño, M. (2010). Transformaciones en el mercado de trabajo (PEA, Empleo, Salarios, Ingresos). En Torrado, S. (Comp.). El costo social del ajuste, pp: 63- 101. Tomo I. Buenos Aires: Ensayo Edhasa.

Artese, M. (2009). La construcción de las representaciones sociales en torno a la protesta social y a la representación institucional. Seis casos de estudio entre los años 1996- 2002 (Tesis de Doctorado en Ciencias Sociales no publicada), UBA, Buenos Aires, Argentina.

Becher, P. (2018). El movimiento de trabajadorxs desocupadxs en Babia Blanca (1995-2003): formas de organización y experiencias de lucha. Bahía Blanca: Acercándonos.

Bonnet, A., y Piva, A. (2009). Argentina en pedazos. Luchas sociales y conflictos interburgueses en la crisis de la convertibilidad. Buenos Aires: Peña Lillo- Ed- Continente. 
Pablo Ariel Becher. Las organizaciones de trabajadores desocupados en Bahía Blanca: un análisis so...

Cotarelo, M. (2016). Argentina (1993-2010). El proceso de formación de una fuerza social, PIMSA. Buenos Aires: Imago Mundi.

D'Amico, M., y Pinedo, J. (2009). Debates y derivas en investigaciones sobre los piqueteros. Una bitácora de lectura. Revista Sociohistórica, 25, 155-180.

Galafassi, G. (2017). Conflictividad social, contradicción y complejidad: entre las clases y los movimientos sociales. Quilmes: Ed. Theomai Geach

Gómez, M. (2012). El Regreso de las clases. Buenos Aires: Editorial Biblos.

Gorenstein, S., Cerioni, L., y Scudelati, M. (1995). Repercusiones laborales de los procesos de privatización en Bahía Blanca. En Estudios de trabajo, 17, 49- 76.

Iñigo Carrera, N. (2008). El concepto de clase obrera. Revista de Estudios Sociales y Maritimos, 1, 101-120.

Heredia Chaz, E. (2018). La "tercera fundación" de Bahía Blanca: la ciudad en la transformación neoliberal. En Heredia Chaz, E. (comp.). Cuaderno N 6. Colección Cuadernos de Historias del Sur Bonaerense, pp: 18. 73. Bahía Blanca: Ediuns.

Klachko, P. (2008). Las formas de organización emergentes del ciclo de la rebelión popular de diciembre 1993 a junio 2002 en la Argentina. Realidad Económica, 234, 80-101.

Mazzeo, M. (2004).Piqueteros. Notas para una tipología. Buenos Aires: FISyP.

Oviedo, L. (2004). Una historia del movimiento piquetero. De las primeras Coordinadoras al Argentinazo. Buenos Aires: Rumbos.

Pérez Álvarez, G. (2013). Patagonia. Conflictividad social y neoliberalismo. El noreste de Chubut (1990-2005), Buenos Aires: Imago Mundi.

Piva, A. (2012). Acumulación y Hegemonia en la Argentina menemista. Buenos Aires: Biblos.

Schorr, M. (2005). Modelo nacional industrial. Limites y posibilidades. Buenos Aires: Capital Intelectual.

Romero Wimer, F. (2013). Las organizaciones de izquierda de Bahía Blanca y la rebelión popular de diciembre de 2001. En G. Hernández (Comp.), Lo dicho y los hechos (pp. 155- 182). Bahía Blanca: Ed. El Colectivo,.

Soul, J. (2012). Transformaciones en las estrategias sindicales en contextos de reconversión productiva. Un estudio de caso en la industria siderúrgica. En AAVV, El mundo del trabajo en América Latina. Tendencias y resistencias. Buenos Aires: CLACSO-CICCUS.

Svampa, M., y Pereyra, S. (2003). Entre la ruta y el barrio: la experiencia de las organizaciones piqueteras, $2^{\mathrm{a}}$ ed. Buenos Aires: Biblos.

Svampa, M. (2008). Cambio de época: movimientos sociales y poder político. Buenos Aires: El Colectivo.

\section{Notas}

1 En este sentido, se plantea la conformación de las clases más allá de su sentido economicista para pensarlas en forma relacional, en su movimiento (Iñigo Carrera, 2008). Las clases no luchan individualmente, sino que se expresan en la conformación de fuerzas en movimiento, impulsadas por tensiones políticas. Una alianza de clases o de diversas fuerzas sociales antagónicas se establece cuando se produce una confluencia objetiva de intereses, observable a partir de las acciones que los sujetos desarrollan en el marco de los enfrentamientos sociales. Los MTDs fueron actores claves dentro delas diversas fuerzas sociales en disputa (Cotarelo, 2016).

2 Se comprende que los procesos a nivel provincial, nacional e internacional impactaron fuertemente en las acciones estratégicas de diversos grupos sociales, incluyendo a los MTDS, pero en este trabajo solo se hará hincapié en el estudio de caso a nivel local, por una cuestión de espacio.

3 Estos dos periódicos fueron los más importantes y de mayor alcance en la ciudad durante el período de análisis. La Nueva Provincia diario tradicional de Bahía Blanca, nacido en 1898, perteneció en sus comienzos a Enrique Julio y posteriormente a la familia Massot. En la actualidad fue vendido al empresario de transporte Gustavo Elías (2016), y cambió su nombre por La Nueva. Con una extensión considerable en el servicio de multimedios, ha trasmitido información local y regional de un modo persistente en el tiempo. Se le ha criticado su tendencia conservadora y ligada a los sectores de las clases dominantes. EcoDias es un diario más reciente creado en el 2000 por un grupo de sectores que profundizaron una mirada reivindicativa hacia la economía social, los derechos humanos, la solidaridad hacia los 
sectores empobrecidos y el cuidado del medio ambiente, entre otros temas. Este diario aportará a una visión crítica más progresista dentro del espectro político local.

4 Los nombres de los entrevistados han sido cambiados por nombres de fantasía para proteger la identidad de los mismos. Todas ellas fueron realizadas por el autor que aparece como PB.

5 A fin de intentar comprender el fenómeno en su totalidad, se recurrió al concepto de población sobrante, que permite incluir no solo a la población desempleo abierto de la EPH, sino también todos los conjuntos poblacionales (subocupados, sobreocupados, jóvenes, niños y jubilados que ingresan al mercado de trabajo, empleo no registrado, trabajadores informales, etc.). En este sentido, la población sobrante se volvió estructural en la ciudad de Bahía Blanca, y pasó a formar parte de la dinámica del capitalismo local, no solo en sus etapas de crisis sino también como forma de acumulación permanente y de control social sobre la población ocupada. La población pauperizada comenzó a recibir programas de asistencialismo que requerían una contraprestación laboral o fueron beneficiarios directos de entrega de alimentos.

6 En Neuquén se produce en el año 1995 una Coordinadora de Desocupados, que será el antecedente inmediato de las grandes puebladas en Cutral-Có y Plaza Huincul.

7 Dos sindicatos mayoritarios en cantidad de afiliados tuvieron una sucesión de conflictos intersindicales, en los que se enfrentaron facciones internas utilizando la toma de sus respectivos locales, ocupaciones, manifestaciones y acciones judiciales. Esto sucedió tanto en la Unión de Obreros de la Construcción República Argentina (UOCRA) como en la Asociación Empleados de Comercio (AEC).

8 Izquierda Unida se planteaba como un partido político que agrupaba varias organizaciones de izquierda, con el objetivo de construir unidad para pasar a la ofensiva en un contexto de desmantelamiento estatal y ataque a todos los derechos sociales y laborales conquistados por los sectores obreros y populares. Un sector del trotskismo (MAS) y del PC habían coincidido en generar un proceso de asociación que tuvo un momento importante de protagonismo electoral, pero que luego se disolvió por diversos problemas internos.(María, comunicación personal, 18 de abril de 2015.

9 Carta programática de la UTD, escrita con máquina de escribir, con fecha 20 de febrero de 1995. Documento cedido por Gerardo.

10 La UTD finalmente fue reconocida como entidad de bien público por el Municipio de Bahía Blanca bajo el número 448, mediante resolución de fecha 14 de julio de 1998, dictada por el expediente 0/00- 5394- 98.

11 Entre los sindicatos que aglutinaba la CTA se encontraba ATE, los docentes nucleados en SUTEBA, un sector de los bancarios y la Asociación Judicial Bonaerense. Más adelante, la misma CTA será la impulsora de la creación de cooperativas como una salida al acampe en la plaza

12 Comunicado volante de la Utd, 11 de octubre de 1995.

13 Las disidencias entre los desocupados llevaron a la conformación de otras organizaciones, algunas auspiciadas por la Iglesia y otras por otras organizaciones políticas como fue el caso de Asociación Desocupados del Sur (ADS). Esta organización acordó sobre la necesidad de continuar la lucha fuera de la plaza. Tuvieron una existencia esporádica.

14 Luego de los PROAS aparecerán los PRENOM, de tinte local y más tarde los planes provinciales y nacionales, como los planes Trabajar y Barrios Bonaerenses.

15 Un sector de la Iglesia, principalmente vinculado a Caritas, actuó durante el conflicto de los desocupados en la plaza en 1995, como intermediario entre el poder político y los desocupados. Esta situación, sin embargo, no fue denunciada como de dependencia, ni atacada por las organizaciones de desocupados, que veían el apoyo de la Iglesia como una acción más en su favor. Los integrantes de Caritas se ganaron el aprecio de los desocupados cuando aportaron alimentos para la olla popular, con esfuerzos por fuera de su colecta anual. Posteriormente, acompañaron el proyecto de la UTD en la venta de ataúdes fúnebres y también impulsarían la construcción de viviendas otorgando créditos para la autoconstrucción de las familias pobres bahienses. A este primer acto le sucedieron el desarrollo de emprendimientos productivos, talleres y capacitaciones en oficios, y la aplicación de proyectos interdiocesanos que a nivel nacional pugnaban por mejorar la educación, el trabajo y la posibilidad de adquirir una vivienda. Estos datos fueron suministrados en una entrevista al entonces presidente de Caritas Bahía Blanca llamado Fernando, 8 de octubre de 2015.

16 El 31 de julio de 2001 la sede de la UOCRA fue escenario de un gran conflicto interno. Ese día se convocó a una asamblea plenaria con la idea de resolver las cuestiones de la falta de empleo y las disidencias internas. Fueron todas las agrupaciones y lista internas. Sin embargo, 100 partidarios de la facción oficialista de la UOCRA se congregaron en la sede local para sacar a los "ocupantes", con denuncias de usurpación. Los trabajadores que estaban en asamblea fueron desalojados a palazos, patadas y puñetazos, y varios de ellos quedaron muy golpeados, algunos con lesiones graves de arma blanca. Se quemaron muebles y computadoras de la sede gremial, y hubo quejas por la ausencia de efectivos policiales. Frente a la gravedad de la situación, la UOCRA nacional envió una comisión para investigar. LNP, 1 de agosto de 2001, portada y pp. 4 y 5. También se pueden ver noticias en diarios nacionales como Clarín y Pagina 12 sobre los sucesos.

17 Algunos datos del entramado político fueron proporcionados en una entrevista a Ernesto, docente y dirigente sindical, participante de Docentes Indignados y de SUTEBA, realizada por PB a través de correo electrónico, 27 de febrero de 2017. 
18 Entrevista a Carlos, ídem ant. Recordemos que el estado de sitio fue decretado por De la Rúa ante la embestida de los sectores populares, medios y obreros en medio de una crisis terminal de la situación política y económica del país. Cf: Clarin, 21 de diciembre de 2001, portada

19 Volante de Bahía Blanca en Lucha, 2001

20 Entrevista a Andrés y otros delegados sobre la Asamblea Nacional, en la Revista Lucha Socialista, p. 5 y también Cartas enviada al Bloque piquetero, 10 de abril de 2002

21 Extracto del diario personal de Andrés, que relata los sucesos escritos a mano, sin fecha precisa.

22 Las referencias de las entrevistas a los participantes de esos hechos fueron corroboradas con la copia de la denuncia realizada en fiscalía el 22 de mayo de 2002 en el marco de la causa 450B1, expediente judicial.

23 Carta abierta enviada por los procesados en búsqueda de solidaridad (original de 2002).

24 Se llamaba en numerosos volantes a sumarse a las reuniones en los barrios, Maldonado (Ricchieri 2889 los viernes 1830) Villa Delfina (Ecuador 2831 los lunes 1830) y los miércoles desde las 9 de la mañana en la mesa de difusión en la Plaza Rivadavia, para que cualquier persona llevara su reclamo o demanda.

25 Volante de Bahía Blanca en Lucha, año 2002.

26 Como sentido general del proceso de lucha, pueden aparecer no una, sino varias estrategias y variables dentro de una estrategia general. En la expresión de estas proyecciones y tendencias se encuentra la lógica de las alianzas sociales entre clases o fracciones que intentan llevar un programa común (Pérez Álvarez, 2013). Más allá de las contradicciones que se generan en el uso y la definición del concepto de estrategia, resulta interesante incluir las prácticas y tradiciones que constituyen las relaciones entre los trabajadores de base y las organizaciones sindicales. El abordaje de la estrategia permite reflexionar sobre los procesos de construcción de la propia representación gremial y con las formas de constitución de los colectivos reivindicativos (Soul, 2012).

27 Las narrativas de los entrevistados invitan a reflexionar sobre las diferencias referentes jóvenes (que aparecen con fuerza a partir del 2000) y los referentes o líderes con experiencia sindical (siempre varones en este caso) o territorial -que son las cabezas de las agrupaciones de mediados de los 90 con trayectorias de lucha-. En el discurso de los líderes o referentes aparece expresada la idea de incorporar la conciencia política y efectuar una vida militante comprometida con los ideales "revolucionarios". En cambio, las bases tienen discursos más reticentes y complejos, donde aparecen motivaciones de participación política, experiencias de vida asociadas al maltrato, a las injusticias vividas diariamente y a la búsqueda de un beneficio material para su familia. Esta última opción no debe plantearse como una mera "acción instrumentalista", ya que en el fondo encierra procesos de politización que formalizan, en muchos casos, objetivos inmediatos, compromiso con la organización y reconocimiento que tienen de la misma.

28 La cuestión de los sectores inmigrantes dentro de la organización y el rol de la mujer que significaba la continuidad de actividades domésticas en el ámbito organizacional son temas que se complejizan en un estudio más abarcativo (Becher, 2018).

\section{BY-NC-SA}

